\title{
Contribuições da racionalidade argumentativa para a abordagem da ética na escola
}

Renato José de Oliveira

Universidade Federal do Rio de Janeiro

\section{Resumo}

Este artigo discute o trabalho com a ética na escola (ensinos fundamental e médio) a partir de uma crítica ao modelo de racionalidade demonstrativa, predominante desde o advento da modernidade. Como alternativa, apresenta outro modelo, a racionalidade argumentativa, discutida com base nas abordagens feitas por Chaïm Perelman, Lucie Olbrechts-Tyteca e Michel Meyer. Os dois primeiros autores formularam uma teoria da argumentação cujo objetivo é subsidiar os raciocínios próprios das ciências humanas e sociais, áreas do conhecimento nas quais procedimentos típicos da racionalidade demonstrativa, como a dedução e o cálculo, não se aplicam. Já Meyer salienta a natureza problematizadora da racionalidade argumentativa, situando a retórica como meio de negociar as distâncias existentes entre os indivíduos a propósito de determinadas questões. Esse quadro teórico é complementado pela filosofia do pluralismo, apontada por Perelman como contraponto às visões de mundo alicerçadas sobre concepções unitárias da verdade, denominadas monismos. Nos marcos desses referenciais, a concepção ética universalista de Immanuel Kant e o relativismo proposto pela ética da estética defendida por Michel Maffesoli são discutidos. Em um segundo tópico, a ética na educação escolar é problematizada tendo em vista a seguinte questão: como formar o caráter do aluno sem recair em algum tipo de doutrinação? Na medida em que ética e moral dizem respeito a essa questão, discutimos como os dois termos vêm sendo compreendidos e propomos tomá-los como instâncias intercambiáveis. As conclusões que apresentamos com base nessas discussões não objetivam solucionar os problemas inerentes aos hábitos e às atitudes dos discentes, mas colocam-se como contribuições para a reflexão dos docentes acerca de suas práticas pedagógicas.

\section{Palavras-chave}

Racionalidade argumentativa - Ética - Pluralismo - Discurso - Educação escolar

Correspondência:

Renato José de Oliveira

rj-oliveira1958@uol.com.br 


\title{
Contributions of argumentative rationality for addressing ethics in school
}

Renato José de Oliveira

Federal University of Rio de Janeiro

\begin{abstract}
This article discusses the work on ethics in school (primary and secondary education) with basis on a critique of the model of demonstrative rationality, prevalent since the advent of modernity. Alternatively, it presents another model, the argumentative rationality one, which is discussed with basis on the approaches taken by Chaïm Perelman, Lucie Olbrechts-Tyteca and Michel Meyer. The first two authors have formulated a theory of argumentation whose goal is to support the typical reasoning of human and social sciences, knowledge areas in which typical procedures of demonstrative rationality, such as deduction and calculation do not apply. Meyer stresses the problematizing nature of argumentative rationality, placing the rhetoric as a means of negotiating the distance between individuals in regard to certain issues. This theoretical framework is complemented by the philosophy of pluralism appointed by Perelman as a counterpoint to the worldviews grounded on unitary conceptions of truth, called monisms. In this theoretical framework, I discuss the universalistic ethical concept of Kant and the relativism proposed by the ethics of aesthetics defended by Maffesoli. In a second topic, ethics in school education is problematized in view of the question: how can one shape the character of the student without falling into some sort of indoctrination? To the extent that ethics and morality relate to this question, I discuss how the two terms have been understood and I propose to regard them as interchangeable instances. The conclusions I present based on these discussions aim not to solve the problems inherent in the habits and attitudes of students, but to contribute to teachers' reflection about their teaching practices.
\end{abstract}

\section{Keywords}

Argumentative rationality - Ethics - Pluralism - Discourse - School education 
A discussão ética atravessa hoje o fazer educativo em diferentes espaços sociais. Nas escolas, nos lares, nas associações comunitárias, nos grupos recreativos e religiosos etc., surgem indagações sobre como os indivíduos veem a si mesmos e aos outros com quem se relacionam. Considerar o outro como espelho dos próprios valores e crenças ou tomá-lo como adversário a ser sobrepujado são posturas que entram em choque com o que pode ser compreendido como ação ética:

Numa palavra, podemos dizer que a ação ética é a negação das diferentes formas de egoísmo através do que se frustra o processo de conquista da humanidade do homem pela destruição da essencial relacionalidade que o constitui como homem (OLIVEIRA, 1995, p. 96).

Na esteira da Ilustração do século XVIII, a racionalidade humana tem-se colocado como condição essencial para ultrapassar os limites impostos pelo egoísmo e pela própria natureza. Immanuel Kant, por exemplo, chamou a atenção para o livre desenvolvimento da criança nas fases iniciais de seu crescimento, em que a ação da natureza seria preferível à intervenção do adulto no que concerne à aquisição dos primeiros conhecimentos acerca do mundo. Ele defendeu, porém, que a formação moral e a disciplina dependiam do desenvolvimento da razão, sendo necessária a ação direta dos educadores para conduzir a passagem do estado natural (animalidade) ao estado social (humanidade). Educação e moralidade foram vistas, portanto, como atributos que moldam o indivíduo, condicionando seu modo de pensar e suas futuras ações:

o homem só se torna homem por meio da educação. Ele é o que a educação faz dele. É importante destacar que o homem só é educado por homens que tenham sido igualmente educados. (KANT, 1996, p. 73)
Há, na formulação kantiana, o determinismo típico de uma razão que, amparada pelas certezas da dedução e do cálculo, considera possível traçar inequivocamente os passos da formação humana, convertendo a moralidade e a educação em bens que devem ser adquiridos. Nessa perspectiva, os que julgam ter feito tal aquisição acabam por excluir aqueles que discrepam do padrão admitido como culto, educado e conforme aos bons hábitos e costumes. A exclusão estimula toda sorte de discriminações contra as culturas que não atingiram o padrão hegemônico, fazendo circular, capilarmente, a intolerância e a animosidade.

A ética ocidental segue sendo, como frisa Alain Badiou (1995), uma ética do não mal, isto é, um conjunto de prescrições que chega facilmente ao consenso sobre como evitar o errado, sem ter capacidade, porém, de pensar propositivamente acerca do que deve ser feito. Tal ética não se mostra consistente, porque a realidade visível é

o desencadeamento dos egoísmos, a desaparição ou a extrema precariedade das políticas de emancipação, a multiplicação das violências étnicas e a universalidade da concorrência selvagem. (p. 24)

Partimos, então, da crítica ao modelo de racionalidade predominante desde o advento da modernidade (racionalidade demonstrativa), o qual subsidia concepções éticas/morais de cunho prescritivo, e apresentamos outro modelo, o da racionalidade argumentativa, como alternativa para o trabalho com a ética/moral na escola de hoje. Nosso problema - a ocorrência de práticas pedagógicas que apenas prescrevem o que é bom ou mau, certo ou errado, justo ou injusto, sem promover, por meio do confronto entre diferentes argumentos, a discussão dessas noções - é focalizado com base na seguinte questão: como formar o caráter do aluno sem recair em algum tipo de doutrinação? Antes de desenvolvê-la, porém, buscamos situar o que vem sendo compreendido por ética e por mo- 
ral, propondo uma abordagem que toma esses termos como intercambiáveis. Por fim, tecemos algumas considerações voltadas para a reflexão dos docentes acerca do trabalho desenvolvido com a ética/moral no cotidiano escolar.

\section{Racionalidade argumentativa e pluralismo}

0 século XVI representou um corte em relação às concepções de mundo e de homem dominantes desde o fim da Antiguidade. Eventos como o Renascimento, os grandes descobrimentos marítimos e as reformas cristãs, entre outros, fomentaram uma mudança em relação à posição de centralidade ocupada pelo homem no cosmo. Segundo Alexandre Koyré (1986), a modernidade instalou-se em meio aos abalos e turbulências produzidos no modo como o homem compreende o mundo, ancorando-se em uma única certeza: "se nada é seguro, só o erro é certo" (p. 25).

Um novo modelo de racionalidade emergiu, então, em um cenário no qual as dúvidas e os questionamentos em relação aos conhecimentos solidamente constituídos faziam do mundo um instigante "amontoado de escombros” (p. 26); estes, todavia, não poderiam persistir a menos que fossem trabalhados de forma metódica, isto é, como pontos de partida para a elaboração de novas certezas. Tal foi o caminho trilhado por René Descartes (1979), que, ao final de sua quinta meditação, reencontrou a rota das ideias claras, julgando-se capaz de poder "adquirir uma ciência perfeita sobre a infınidade das coisas, não só das que estão em Deus, mas também das que pertencem à natureza corporal" (p. 171).

Com o advento dos ideais iluministas, no século XVIII, afirmou-se o princípio da subjetividade: as sociedades passaram a ser compreendidas como sendo formadas por indivíduos autônomos que escolhem os próprios destinos. Tal princípio encarnava as aspirações do homem burguês, que pretendia universalizar sua visão de mundo. Assim, os direitos à vida, à propriedade, à liberdade de pensamento e de expressão, à educação, consagrados pela Ilustração, passaram a ser vistos como direitos fundamentais do homem.

0 modelo de racionalidade dominante entre os filósofos iluministas, porém, seguiu sendo o demonstrativo, que opera por meio da dedução e do cálculo, rechaçando os raciocínios baseados no que é plausível e que não conduzem a certezas definitivas. John Locke (1997), cuja influência sobre pensadores como Voltaire, Montesquieu, Rousseau e Kant foi significativa, considerava a moral passível de demonstração, assumindo o pressuposto de que todos os homens têm a ideia clara de um ser perfeito, o qual figuraria como expressão maior da bondade. Assim sendo, ele entendia que as mesmas noções do certo e do errado poderiam ser alcançadas por quem se empenhasse em procurá-las com o afinco empregado no estudo das ciências do mundo.

Chaïm Perelman (1972) critica a redução de toda racionalidade a apenas uma de suas formas, assinalando:

Se há três séculos nossa tradição filosófica pode ser caracterizada por sua concepção particular de razão, cujas únicas manifestações seriam a prova demonstrativa e o cálculo, todo homem considera que está raciocinando quando delibera, discute, argumenta ou justifica uma atitude. E esse fato é reconhecido implicitamente mesmo por aqueles que limitam a competência da razão ao aspecto formal do saber, pois, para fazer prevalecer seu ponto de vista num debate, não podem recorrer nem ao cálculo, nem à demonstração formal, mas à argumentação, que é o único uso possível da razão no caso. (p. 98)

Esse reducionismo acaba por estabelecer uma rígida distinção entre o verdadeiro e o falso, entre o justo e o injusto, sendo típico das concepções que Perelman classifica como 
monistas ${ }^{1}$, as quais, embora geralmente forneçam uma visão sistematizada e racionalizada do universo, não deixam de ter limitações:

O inconveniente das ideologias monistas é o de favorecer um reducionismo às vezes difícil de tolerar. Quando não conseguem fazer prevalecer seus pontos de vista, podem justificar em nome de Deus, da razão, da verdade, do interesse do Estado ou do partido o recurso à violência, o uso da força contra os recalcitrantes. (p. 6-7)

As concepções de inspiração pluralista, ao contrário, rechaçam a ideia de que qualquer visão de mundo possa ser detentora do monopólio da verdade. Elas conclamam os homens a debaterem seus pontos de vista, os quais devem ser apresentados por meio de argumentos. Chaïm Perelman e Lucie Olbrechts-Tyteca (1996) discutiram que, à diferença dos raciocínios formalizados que têm lugar na lógica e nas ciências matemáticas, as ciências humanas trabalham com raciocínios de natureza não coerciva, isto é, que não impõem a todos as mesmas conclusões necessárias. Se afirmamos, por exemplo, que Sócrates é homem e, portanto, mortal, temos necessariamente a concordância de qualquer ser racional, já que todos os homens morrem. Nesse caso, o raciocínio é coercivo. Se afirmarmos, porém, que Maria é mãe e por isso ama seu filho, estaremos diante de um raciocínio não coercivo, pois não necessariamente todas as mães amam seus filhos. Tais raciocínios são chamados de retóricos e foram estudados pelos autores a partir de uma teoria da argumentação, também denominada nova retórica.

A teoria da argumentação acima mencionada considera orador todo aquele que elabora um discurso, falado ou escrito, voltado para a persuasão de outrem. 0 discurso pode ser um texto ou um enunciado cujo conteúdo sugira mais do que a simples descrição de

1 - A palavra é derivada do conceito leibniziano de mônada, o qual, resumidamente, consiste em uma totalidade fechada em si mesma. um fato ou a comunicação de uma regra. Por exemplo: os enunciados $O$ céu está azul hoje e É proibido fumar não possuem conteúdo persuasivo porque, no primeiro caso, há tão somente a constatação de um dado objetivo da realidade, e, no segundo, a interdição sumária de um tipo de ação. Entretanto, os enunciados O céu está azul hoje, mas o dia é triste e É proibido proibir são de tipo retórico. Isso porque, em ambos os casos, existe a busca da persuasão de outrem a partir do estabelecimento de algum tipo de acordo acerca dos juízos emitidos pelo orador.

Já o conjunto de pessoas que o orador quer persuadir com seu discurso é denominado auditório. Os auditórios variam muito em composição e extensão. Podemos ter auditórios particulares (professores, médicos, católicos, socialistas etc.), auditórios de elite (formados por grupos que se apresentam como modelos às demais pessoas) e mesmo o auditório universal, que encarna a visão do orador acerca do conjunto dos homens razoáveis. 0 auditório universal não é uma realidade física, mas, antes, a expressão de determinada imagem do homem construída pelo orador, a qual se modifica no curso da temporalidade histórica e também conforme as influências sociais e culturais.

Nos processos de persuasão, o orador pretende mostrar a legitimidade das teses que defende, a qual se acha assentada sobre a verossimilhança. Já Aristóteles (1983) sublinhava ser preciso fundar a argumentação sobre lugares ou tópoi característicos. Dentre eles, o lugar do preferivel mereceu destaque por ser aquele que se reportava ao que a maioria dos homens busca ou faz. Se certa regra de conduta, por exemplo, é praticada por inúmeras pessoas e outra apenas por um círculo reduzido, a primeira é preferível à segunda e tal preferência fundamenta os argumentos que, no debate, respectivamente apoiam e criticam essas regras. Os lugares do preferível, entretanto, podem não ser tão óbvios quando se trata de definir valores associados a determinadas situações. Diz-se que a maioria das pessoas admira mais os feitos 
difíceis do que os fáceis, mas, no curso das relações cotidianas, as ações cumpridas com menor esforço são preferíveis às que demandam maior esforço. A existência de controvérsias instiga os oradores a buscar fundamentos em outros tópoi, o que levou Perelman e OlbrechtsTyteca (1996) a redimensionarem a classificação aristotélica, dando ênfase ao que denominaram lugares da quantidade e lugares da qualidade.

Os lugares da quantidade oferecem meios para medir o valor de uma argumentação a partir de critérios como estabilidade e utilidade, dos quais deriva o conceito de normalidade como parâmetro capaz de persuadir os indivíduos a fazerem o que a maioria faz e também de dissuadi-los de fazer o contrário. Muitas vezes, porém, a persuasão é mais profunda quando os argumentos empregados tocam a alma humana por seu caráter singular, original e até mesmo excêntrico. Nesses casos, os lugares em pauta são os da qualidade, que se valem da natureza sedutora do romântico, do obscuro, do irrepetível.

Enquanto valor qualitativo que se opõe ao valor quantitativo da estabilidade, a precariedade pode apelar para a finitude da vida. A expressão latina Carpe diem (aproveitem o dia) busca justamente mostrar que o normal, o sensato, o comedido etc., podem apenas ser máscaras que desfiguram a face do viver. No bojo dos processos argumentativos que marcam a interação de um orador com seu auditório, está em jogo, portanto, o propósito de predispor alguém a agir; contudo, nenhum auditório pode ser visto como uma tabula rasa que se deixa moldar, de sorte que é preciso destacar o caráter variável das adesões emprestadas às teses submetidas. A variabilidade da adesão é sempre um limite quando certos oradores buscam estabelecer vínculos inexoráveis entre as consequências de um fato e sua causa. Nesses casos, quer-se fazer a transferência direta do valor do efeito para o valor da causa (argumentação pragmática), convertendo, por exemplo, a justiça em um simples princípio de ação e reação: fazemos ao outro exatamente aquilo que ele nos fez. A pena de Talião (olho por olho, dente por dente) ilustra esse tipo de transferência que, durante séculos, tem alimentado o ódio e o espírito de retaliação entre os homens.

A abordagem desenvolvida por Perelman e Olbrechts-Tyteca questiona, assim, as doutrinas que se apoiam sobre verdades absolutas, aplicando-se tanto ao plano do conhecimento filosófico, quanto à esfera do conhecimento comum ou cotidiano. Por certo, as exigências e o rigor necessários quanto à coordenação dos elementos expostos na argumentação cotidiana não são os mesmos que aqueles exigidos na argumentação filosófica; isso, todavia, não é razão para sobrevalorizar uma forma de conhecimento em relação à outra. Elas se aplicam a domínios distintos, e questionar a hierarquização muitas vezes estabelecida entre conhecimento douto (considerado superior) e conhecimento cotidiano (considerado inferior) passa pela desconstrução dos lugares comuns que sustentam as divisões entre mais sábios e ignorantes, entre cultos e incultos, procurando valorizar as produções culturais, técnicas e científicas elaboradas por diferentes povos e grupos sociais. Isso implica assumir um novo ethos, na medida em que ocorre o reconhecimento do outro como autor e não simplesmente como receptor do que os indivíduos socialmente mais reconhecidos produzem.

No que tange às ações éticas, o monismo faz-se presente tanto nas visões universalistas baseadas em uma concepção única da razão, que seria idêntica e comum a todos os seres pensantes, quanto nas visões relativistas que defendem não ser possível estabelecer critérios para distinguir e valorar as diferentes razões invocadas pelos particularismos éticos. 0 primeiro caso é bem ilustrado pela ética kantiana, segundo a qual, a despeito das diferenças de opinião, de costumes ou de credos religiosos, há imperativos que transcendem às motivações particulares deste ou daquele indivíduo. Um exemplo desse tipo de imperativo ${ }^{2}$ é sempre $d i$ zer a verdade. Se, porém, alguém é forçado a

2- Kant chama tais imperativos de categóricos. 
mentir para evitar danos a si mesmo (quando acusa um inocente em função de algum tipo de coação), esse alguém sentirá remorso, o que, para Kant, serve como prova de que os indivíduos têm o dever moral (universal e comum a todos) de dizer sempre a verdade. Além disso, independentemente do remorso, o bem desfrutado pelo mentiroso é contingente, porque, se o ato de mentir possuísse estatuto de universalidade, todos mentiriam sempre, tornando a convivência social insuportável. Badiou (1995), entretanto, chama a atenção para o fato de que o sujeito universal kantiano não é outro senão o homem europeu, branco e cristão que, em nome da ética do não mal, universaliza suas verdades morais, estéticas, políticas etc.

0 segundo caso pode ser exemplificado a partir da ética da estética, a qual, segundo Michel Maffesoli (1990), acha-se fundada sobre as emoções. Tal ética é tributária das facções e dos grupos que se multiplicam em um mundo apenas formalmente regido pelos valores da modernidade, os quais, contudo, esfumam-se porque os homens, não tendo mais identificação com as instituições políticas e sociais, reúnem-se em tribos em que se reconhecem e que lhes permitem expressar suas vozes, desejos e interesses, ainda que, por vezes, de modo violento. Na medida em que vivem em "um mundo passional, um mundo que supera a ordem rígida da razão" (MAFFESOLI, 1985, p. 30), a sociabilidade, ligada a uma ideia de cooperação entre os indivíduos, ter-se-ia esgotado, dando lugar a uma nova realidade na qual o homem não é mais o ser social que visa ao bem comum, mas um ser para a tribo, que muitas vezes vive contra outras tribos.

0 monismo de uma razão totalizante, por um lado, e o das emoções alheias a qualquer apelo da racionalidade, por outro, dispensam o recurso aos procedimentos argumentativos como meios de se chegar a soluções razoáveis para situações conflituosas, aumentando a estranheza e o distanciamento entre os diferentes.

Buscando ampliar os estudos contemporâneos sobre a argumentação, Michel Meyer (1998) concebe a retórica como processo por meio do qual os indivíduos negociam as distâncias existentes entre eles a propósito de uma questão ou problema. Ele considera importante analisar a intencionalidade presente em um discurso, atribuindo-lhe razões e tomando-o como problema. Embora muitos oradores julguem que seus discursos respondem a todas as possiveis questões, Meyer (1998) sublinha que somente respostas de tipo apocrítico, como Sócrates é mortal, acham-se imunes ao questionamento. Isso significa dizer que, na interação entre o orador e o auditório, há uma interrogatividade subjacente cuja eliminação nunca é total, permitindo o surgimento de novas questões:

para que surja uma nova questão, é preciso haver necessariamente uma mediação por meio da qual resulte problematizado o que estava fora de questão. (p. 22)

É essa função mediadora e problematizadora que a retórica propõe desenvolver.

\section{Problematizando a ética na educação escolar}

No Brasil, durante o período do regime militar, o termo ética era pouco empregado na educação escolar, já que a opção se dava pelo ensino da Educação Moral e Cívica (EMC), a qual, conforme o Artigo $2^{\circ}$ do Decreto $\mathrm{n}^{\circ}$ 68.065, de 14 de janeiro de $1971^{3}$, deveria fazer parte de todos os sistemas de ensino, não só como disciplina, mas também como prática educativa. Segundo Vanessa Kern de Abreu e Geraldo Inácio Filho (2006), a EMC não era apenas mais uma atividade no currículo escolar, figurando também como instrumento de doutrinação vinculado à política de Segurança Nacional. Essa visão é também corroborada por Luiz Antônio Cunha (2007), para quem a EMC consistiu em uma fusão do pensamento católico

3- Este decreto, na verdade, regulamentou o Decreto-Lei $n^{\circ} 869$, de setembro de 1969, assinado pelos ministros do Exército, da Marinha e da Aeronáutica, que tornou a EMC obrigatória em todos os níveis de ensino. 
conservador com a referida política, consoante as prescrições da Escola Superior de Guerra. 0 autor salienta, ainda, que a redemocratização do país, iniciada em 1986 com a chegada de José Sarney à Presidência da República, levou a EMC a um longo processo de agonia, que culminou com sua revogação oficial como disciplina (Lei $n^{\circ}$ 8.663/93).

A supressão da EMC dos currículos escolares contribuiu para que a formação do caráter das crianças e dos adolescentes não fosse mais encarada como cruzada contra os inimigos da pátria, sendo pensada como processo que busca dar subsídios para que o aluno possa vir a ser um cidadão consciente de seus direitos e deveres. Os Parâmetros Curriculares Nacionais (PCN) do ensino fundamental (terceiro e quarto ciclos), em fins da década de 1990, ressaltaram, por exemplo, a importância de a ética ser trabalhada como um tema transversal que permeasse os conteúdos de todas as disciplinas (BRASIL, 1998a). Tal proposta teve, inegavelmente, o mérito de buscar comprometer todo o corpo docente - e não apenas os professores de determinadas disciplinas - com a responsabilidade de desenvolver o trabalho com a ética na escola, buscando assim propiciar condições para o cumprimento do que fora previsto na Lei de Diretrizes e Bases (LDB, Lei $\mathrm{n}^{\circ}$ 9.394/96) acerca da formação para o exercício da cidadania. Nessa mesma linha de ação, as Diretrizes Curriculares Nacionais (DCN) para o ensino fundamental reafirmaram esse propósito ao destacarem que as escolas devem orientar-se pelos "princípios éticos da autonomia, da responsabilidade, da solidariedade e do respeito ao bem comum" (BRASIL, 1998b, p. 4).

A implementação desses objetivos a partir de práticas pedagógicas não prescritivas suscita a seguinte questão: como formar o caráter do aluno, tendo em vista o exercício da criticidade, sem recair em algum tipo de doutrinação? Porém, antes de discuti-la, consideramos oportuno discutir o que vem sendo compreendido por ética e por moral.

$\mathrm{Na}$ abordagem da filosofia especulativa alemã, a ética foi situada acima da moral, como em Friedrich Schelling (1980), que entendia ser esta última um imperativo dirigido ao indivíduo, ao passo que a primeira consistiria em um imperativo dirigido a uma comunidade de seres morais. A noção de comunidade moral marcou o pensamento pós-kantiano, como em Ernst Tugendhat (1997), que a vê como instância em que "todos exigem de todos - relativamente à sanção interna - serem bons membros da sociedade, em um determinado sentido de bom" (p. 64). A pertença a essa comunidade não é determinada a priori pela razão universal (como em Kant), mas desejada pelo indivíduo, que passa a aceitar a sanção interna (sentimento de vergonha) toda vez que fere as normas estabelecidas pela comunidade moral. É a partir desse ato da vontade, então, para Tugendhat, que a ética se constitui, caracterizando-se como “reflexão filosófica sobre a moral” (p. 41).

Já para autores como John Dewey (1958), a moral deveria promover o abandono das reflexões filosóficas de cunho metafísico ou contemplativo em prol do desenvolvimento de métodos investigativos que permitissem mostrar que ela não é um catálogo de regras a serem aplicadas como prescrições médicas, mas resultado de trabalhos de pesquisa. Em vista disso, o critério para o estabelecimento de verdades, a exemplo do que o autor defendia para as demais ciências, deveria ser o do alcance social e não o do apoio em instâncias transumanas como Deus ou a Razão Universal.

Enquanto Dewey vislumbrou uma moral de natureza científica, André Lalande (1993), em seu conceituado dicionário de filosofia, preferiu conferir estatuto de cientificidade à ética, na medida em que esta estabelece juízos de apreciação sobre as ações humanas, qualificando-as como boas ou más. Já a moral, em seu entendimento, constituir-se-ia como conjunto de prescrições assumidas, em dado período histórico, por determinadas sociedades, 
e também como prática de exortar os indivíduos a aceitá-las e segui-las.

As conceituações que situam a moral como objeto de estudo e reflexão da ética são questionadas por alguns sociólogos que se denominam pós-modernos, entre os quais estão Maffesoli (1990) - cuja abordagem incorpora contribuições de filósofos como Friedrich Nietzsche e Michel Foucault - e Zygmunt Bauman (2006), que traz aportes filosóficos de Emmanuel Lévinas. Para o primeiro, conforme já foi comentado, a ética seria tributária de grupos restritos, que estabelecem seus códigos de conduta e podem entrar em choque com grupos rivais, ao passo que a moral visaria à universalidade. Como exemplo, ele cita a Revolução Francesa, que teria difundido a moral burguesa para o conjunto da humanidade.

Bauman (2006), por sua vez, concebe a ética tão somente como conjunto de normas socialmente acordadas, as quais esperamos que sejam cumpridas no dia a dia das relações recíprocas que estabelecemos uns com os outros. A moral, para ele, corresponde à inclinação que um indivíduo tem em relação a outro, ou, mais precisamente, a um desejo de ser para o outro. Em suas análises da realidade atual, o autor aponta como problema o fato de os deveres éticos, que são heterônomos, serem superiores às responsabilidades morais, que são autônomas.

Já Badiou (1995), apoiando-se em Jacques Lacan, critica a pretensão kantiana de formular uma moral universal, bem como a ética contemporânea, por ser uma ética do não mal, conforme já referido. A visão kantiana, recapitulemos, supõe a existência de um homem universal, que não pode tomar as máximas e os imperativos hipotéticos como condicionantes de sua vontade. As máximas são orientações subjetivas - como jamais aceitar uma ofensa de outra pessoa -, que podem servir para determinados indivíduos, mas não necessariamente servirão a todos. Os imperativos hipotéticos, por sua vez, têm natureza objetiva, já que obedecem a relações do tipo consequência-causa: para obter o resultado Y, é preciso realizar a ação X. Ocorre, porém, que nem as máximas nem os imperativos hipotéticos desprendem-se das contingências empíricas que condicionam a vontade, impedindo-a, portanto, de ser livre. Somente quando toda e qualquer empiria for removida, ou seja, quando o dever se impuser apenas por sua natureza de dever, conforme estabelecem os imperativos categóricos, a vontade será livre, pois irá coincidir com a pura forma de uma lei prática: "Age de tal modo que a máxima da tua vontade possa valer sempre ao mesmo tempo como princípio de uma legislação universal" (KANT, 1997, p. 42).

Na visão de Badiou (1995), a lei moral kantiana é de um rigorismo exacerbado e, por isso, a ética que ele sugere vincula-se às situações singulares vividas pelos sujeitos humanos, destacando-se, dentre elas, quatro tipos fundamentais: as situações ligadas à política, ao amor, à ciência e à arte.

Perelman (1996), por sua vez, pensa a moral a partir do Direito e chama a atenção para o fato de que os princípios daquela não são dedutíveis de axiomas gerais, tampouco generalizáveis a partir dos juízos particulares por via indutiva. Ele prefere chamar de filosofia moral o trabalho de reflexão sobre os princípios, regras, valores, hierarquias de valores e costumes que orientam a conduta humana na vida em sociedade, assinalando que, nessa matéria, diferentes concepções podem ser consideradas razoáveis - e, portanto, levadas a exame por meio da racionalidade argumentativa -, o que é próprio de uma filosofia de inspiração pluralista. 0 autor sublinha, ainda, o papel do livre arbítrio na determinação do agir, ou seja, destaca que uma decisão tem caráter moral não porque se conforma ao estabelecido, mas porque faculta ao sujeito obedecer ou não à determinação da autoridade, seja ela de natureza política ou religiosa:

Jamais poderemos, se formos um adepto do livre exame, desvencilhar-nos de nossa responsabilidade argüindo, mesmo de boa fé, que nos limitamos a amoldar-nos às 
ordens de uma autoridade qualquer. Se é verdade que a obediência à autoridade será o mais das vezes, como para Sócrates, a atitude recomendável, cumprirá que seja em virtude de uma decisão de obedecer que, assim como a de desobedecer, não nos permite eludir nossas responsabilidades morais. (p. 327)

Esse breve apanhado - que seguramente não esgota a discussão acerca do que historicamente veio sendo compreendido como ética e como moral - permite, todavia, perceber que as concepções apresentadas por diferentes fontes e autores não são consensuais, muito menos as distinções feitas acerca do que pertence ao domínio da ética e o que pertence ao domínio da moral. Em vista disso, consideramos mais significativo não distinguir tais domínios, salientando que a reflexão, o julgamento e as decisões não são vistos como momentos particulares do sujeito ético, nem as ações consideradas boas ou virtuosas como prerrogativas do sujeito moral, sendo ambos compreendidos como indissociáveis. Tomamos, então, ética e moral como instâncias intercambiáveis que se referem aos mesmos objetos: valores, hierarquias de valores, princípios e hábitos que orientam as reflexões e as ações do homem no contexto de suas múltiplas relações. Ambas são vistas como construções históricas e intersubjetivas que, como não precisam necessariamente recorrer a uma norma transcendente, procuram seus fundamentos normativos nos espaços sociais construídos pelos homens, levando em consideração o que representa a maioria dos casos ou o que é estabelecido pelo consenso da maioria. Tais fundamentos não são apodícticos, mas possuem estatuto epistêmico análogo ao das endoxa ou opiniões geralmente aceitas, conforme a classificação feita por Aristóteles (1983) em Tópicos. A concepção de ética/ moral aqui exposta parece-nos apropriada para o trabalho pedagógico escolar, uma vez que, balizada pela racionalidade argumentativa, permite confrontar diferentes visões de homem e de sociedade.

Com respeito à formação do caráter do aluno, cabe dizer, inicialmente, que a tradição pedagógica que considera a infância e a adolescência apenas como fases preparatórias para a vida adulta concebe a formação do educando como processo por meio do qual a personalidade é moldada conforme preceitos e padrões. Tal tradição, cujas origens remontam à Antiguidade grega (formação do menino para tornar-se herói, no período homérico), foi duramente criticada por Jean-Jacques Rousseau (1995): "Procuram sempre o homem na criança, sem pensar no que ela é antes de ser homem” ( $p$. 4). 0 projeto pedagógico apresentado em Emílio pautava-se em uma educação de tipo indireto, ou seja, o aluno aprendia pela chamada ação das coisas, isto é, pelo contato com objetos ou situações que lhe permitiam vivenciar experiências e delas extrair ensinamentos úteis. 0 preceptor mantinha-se à distância, observando, sem exortar, mediante preleções verbais, o menino à prática de ações virtuosas. Tal princípio pode ser encontrado também em Aristóteles (1992):

Quanto às várias formas de excelência moral, todavia, adquirimo-las por havê-las efetivamente praticado, tal como fazemos com as artes. As coisas que temos de aprender antes de fazer, aprendemo-las fazendo-as - por exemplo, os homens se tornam construtores construindo, e se tornam citaristas tocando cítara; da mesma forma, tornamo-nos justos praticando atos justos, moderados agindo moderadamente, e corajosos agindo corajosamente. (p. 35)

É importante frisar, porém, que o destaque dado por Aristóteles ao aprendizado das virtudes pela ação não significa que ele tenha desconsiderado o exercício de outro tipo de virtudes (dianoéticas), ligado à chamada vida contemplativa. 0 sábio, no entender do Estagirita, era o homem capaz de dominar 
seus pensamentos, ou seja, de refletir sobre si mesmo e encontrar o fim último das ações denominadas boas. Segundo Meyer (1994), Aristóteles achava-se mesmo dividido entre uma ética dos meios voltados para a consecução do bem visado (que era objeto da educação e da deliberação autônoma) e uma ética dos fins em si mesmos (que era objeto do pensamento contemplativo), mas, de todo modo, o fato de não ter conferido importância apenas à ultima foi significativo, pois reservou um lugar para a poiesis (obra ou realização) como dimensão inalienável da vida humana.

Na medida em que defendemos uma educação ética/moral cujos fins são a solidariedade e o respeito mútuo, entendemos que as práticas pedagógicas centradas no prescritivismo não contribuem para realizá-los. Isso porque as prescrições acerca do que é ou não ético não costumam ser problematizadas, levando o aluno a reproduzir a visão de mundo do professor, mas não necessariamente a agir eticamente. Nesse sentido, elas assumem caráter doutrinário, e toda doutrinação, tenha a natureza que tiver - política, ética ou religiosa -, é uma prática de caráter monista que coloca o auditório na condição de objeto, cerceando-o como sujeito das próprias ações.

0 que desejamos, portanto, como educadores, coincide com o que defende Pedro Goergen (2011):

0 que se espera da educação ético-moral é que contribua para ampliar a capacidade reflexiva dos indivíduos para que a autonomia e liberdade subjetivas ampliadas possam ser resgatadas do individualismo hedonista e ser capitalizadas em favor de um novo projeto de transformação social. (p. 121-122)

Nessa perspectiva, a formação ética/moral pode ser trabalhada com maior efetividade, sem que padrões comportamentais sejam ditados:

0 que se pretende a seguir não é oferecer um modelo de "ética pedagógica" em termos de indicação de valores e procedimentos morais que deveriam ser transmitidos aos alunos, mas apresentar uma análise das dificuldades e problemas que a temática envolve. Não se trata apenas de sublinhar as rupturas que a tradição vem sofrendo, mas de dimensionar o entendimento de uma nova realidade que o desenvolvimento social, científico-tecnológico e teórico contemporâneos vem instituindo. (p. 149)

Em termos de um currículo disciplinar, cabe à disciplina filosofia incluir a ética/moral em seus programas, sendo oportuna a menção a diferentes modelos filosóficos, pois ela se coaduna com uma abordagem pedagógica de cunho pluralista. Manfredo Araújo de Oliveira (1995) aponta alguns modelos que podem ser problematizados pelo professor, como o realista, o empirista, o céptico, o transcendental e o dialético; todavia, o trabalho com a ética/moral na escola vai além disso, já que diz respeito à busca pelos fins que elencamos anteriormente, os quais requerem o esforço e o envolvimento de todo o corpo docente. Para que isso seja logrado, a realização de trabalhos interdisciplinares na escola e a articulação de projetos comunitários são iniciativas importantes.

Assim, em vez de trabalharem com prescrições normativas, os professores podem assumir outra postura, fazendo, por exemplo, um balanço crítico de suas ações e formas de conduta antes de iniciarem quaisquer ações pedagógicas. Esse procedimento, chamado por Perelman e Olbrechts-Tyteca (1996) de argumentação consigo mesmo ou diálogo de foro intimo, permite ao docente avaliar as próprias limitações, pois, como qualquer outro ser humano, ele não é modelo de conduta ética.

Além disso, o diálogo estabelece-se quando o docente busca a interlocução com o discente para discutir o que cada um entende por certo e por errado. Os procedimentos argumentativos permitem problematizar formas de comportamento, levando o aluno a perguntar a si mesmo: e se fosse comigo? E se fosse eu o prejudicado e não o responsável 
pelo prejuizo causado ao outro? Eu gostaria disso? São perguntas sobre as quais mesmo as crianças pequenas têm condição de pensar. Ademais, problematizações dessa natureza propiciam que a discussão não seja encerrada por meio de respostas como você não pode prejudicar seu colega, cujo caráter apocrítico parece evidente para o docente, mas não necessariamente o é para o aluno, que pode perfeitamente a elas contrapor: por que não posso, se ele é mau e ninguém na turma gosta dele? Perguntas desse tipo ilustram bem o quanto existem distâncias a serem negociadas (MEYER, 1998) entre os pontos de vista de professores e de alunos acerca de questões de cunho disciplinar e comportamental. Por vezes, os docentes acham que estimular o sentimento de vergonha ou de culpa em relação a uma atitude praticada pelo aluno pode contribuir para a redução dessas distâncias. A esse respeito, porém, é importante ressaltar o que diz Yves de La Taille (2008):

com que idade a criança começa a sentir vergonha moral? Nossos dados (La Taille, 2002) apontam a idade de oito, nove anos. Como para a culpa, a vergonha moral certamente é experimentada antes dessa fase de desenvolvimento, mas ainda de forma tênue e, sobretudo, menos intensa que outros sentimentos. (p. 25)

Ainda, não se pode desconhecer que o sentimento de vergonha tem sobre o estudante o efeito de uma sanção ou punição interna, cujos desdobramentos, muitas vezes, podem ser contrários àqueles esperados pelo professor. Francis Imbert (2001), que discute, a partir de aportes da psicanálise, a ineficácia das punições no que diz respeito ao enfrentamento das transgressões, salienta:

uma vez experimentada, essa vergonha acaba por tornar-se menos sensível. Daí o paradoxo: a punição apresenta o considerável equívoco de melindrar uma das principais molas da vida moral, diminuindo sua eficácia. Ao ser infligida de novo, a sanção acaba por estigmatizar aquele a quem ela se aplica; designa-o como "delinquente" ou, ainda, "sujeito de baixo valor moral"; assim rotulado, categorizado, o delinquente corre o risco de nunca mais parar de cometer faltas. (p. 123)

Desse modo, para reduzir as distâncias, é preferível desenvolver atividades que possibilitem ao professor e ao aluno vivenciarem situações que envolvam o respeito mútuo e a prática de ações solidárias em diferentes níveis. A partir delas, os princípios abstratos e gerais, bem como os juízos de valor concretos e contingentes, podem estabelecer entre si, segundo assinala Perelman (1996), uma dialética por meio da qual se complementem: sempre que o princípio parecer distante demais da realidade vivida, o juízo atuará no sentido de conferir-lhe materialidade; sempre que o juízo for estreito demais, o princípio atuará no sentido de ampliá-lo.

Pedagogicamente, é possível ilustrar esse duplo movimento por meio de algumas situações-problema. Tome-se, por exemplo, o princípio respeitar a vida. Seria ele aplicável a qualquer situação, ou torna-se necessário precisá-lo por meio de juízos de valor concretos? Se toda forma de vida deve ser respeitada, o uso de um simples antisséptico para tratar ferimentos não deveria ser feito, pois mata enormes contingentes de microorganismos. Pela mesma razão, a vítima que é ameaçada de morte não poderia, para defender-se, tirar a vida do agressor. No primeiro caso, conferese concretude ao princípio a partir do juízo que invoca o maior valor da saúde humana e, no segundo, o maior valor do direito à autodefesa. Por sua vez, quando afırmações do tipo quem nega a Deus ofende ao próximo forem apresentadas como regras a serem seguidas por todos, cabe recorrer a princípios gerais como o direito à liberdade de opinião e expressão (Artigo 19 da Declaração Universal 
dos Direitos Humanos, de 1948), que permitem criticar o caráter discriminatório presente nesses juízos.

A via da argumentação no espaço escolar não é, naturalmente, fácil de trilhar. Para muitos professores e gestores, prevalece ainda hoje o entendimento de que os papéis dos sujeitos do processo educativo estão claramente definidos: ao professor, cabe transmitir saberes e disciplinar o comportamento do aluno; ao aluno, cabe aquiescer e respeitar as determinações do professor. Em algumas situações, admite-se que haja um diálogo, à maneira socrático-platônica, por meio do qual o discente é induzido a concluir acerca do que é considerado certo ou errado. No diálogo Mênon, Platão (2010) explica, entretanto, o direcionamento a partir da teoria da reminiscência, segundo a qual o conhecimento preexiste no homem (pois sua alma é imortal e contemplou as verdades eternas no mundo inteligível), sendo a ação do mestre (no caso, Sócrates) apenas a de fazer com que o discípulo resgate aquilo que nele se acha esquecido. Admitindo, porém, que todo conhecimento é adquirido a partir das relações que os indivíduos estabelecem entre si e com o mundo, o processo de redescoberta a partir do acesso a um conhecimento imanente perde o sentido pedagógico que possuía para Platão, que era o de libertar a alma dos erros cometidos em função da comunhão com o mundo sensível.

Nos marcos da racionalidade argumentativa, a educação escolar assume outro foco. Na medida em que se fazem críticas ao absolutismo das verdades (de conhecimento, de comportamento, de condição social etc.), a caracterização do aluno como ser passivo, que apenas ouve e registra o que o professor diz em sala de aula, dá lugar a outra, a qual o toma como ser que se relaciona e argumenta.

Nesse processo, as controvérsias surgem, o que é importante para fazer com que os objetos da discussão ética/moral (valores, normas, princípios, formas de conduta) sejam problematizados e não simplesmente repassados ao discente, do qual se espera que haja adesão, mas não conversão. Se a doutrinação ética/ moral busca converter o aluno por meio do apelo aos seus sentimentos e emoções, ou por meio da imposição de verdades, a argumentação, ao contrário, dirige-se ao ser pleno, constituído de razão e paixões. Ela não se apoia em dogmas de fé nem de credo político, buscando situar o discurso ético/moral no campo do plausível, do razoável. Diferentemente da conversão, a adesão do auditório é, portanto, fruto de uma negociação, sendo variável e sempre passível de revisão.

Sem dúvida, os auditórios discentes nutrem muitas expectativas e os docentes, na condição de oradores, não têm como satisfazêlas completamente. Algumas delas, porém, talvez não lhes exijam grandes esforços, como o desejo manifestado pelos alunos de serem vistos como sujeitos possuidores de história, e não como meros ouvintes de histórias alheias.

\section{Considerações finais}

A racionalidade argumentativa não se coloca como panaceia para os problemas da educação escolar, mas, por estar apoiada na concepção do razoável - segundo a qual as verdades não são absolutas e transcendentes à condição humana, mas, ao contrário, imanentes a ela, sendo forjadas no curso da existência social -, pode contribuir para o desenvolvimento de raciocínios que problematizem normas, valores, princípios e formas de conduta que são, conforme discutimos, objetos próprios da ética/ moral. Sem dúvida, a vida social é atravessada por interesses que fomentam os mais diversos conflitos entre os homens, o que não permite criar ilusões quanto a resolver, de modo cabal, problemas como a discriminação, a intolerância e o egoísmo.

De todo modo, o fomento de práticas argumentativas no espaço escolar permite que professor e aluno passem a ter outros olhares sobre o relacionamento que mantêm entre si. Certamente não há receitas didáticas de como argumentar e problematizar, pois isso dependerá 
da interação, sempre variável, que todo orador estabelece com seu auditório. Nas primeiras séries do ensino fundamental, o professor torna-se mais diretivo devido à assimetria (de saberes e experiências vividas) existente entre ele e os alunos. A maior diretividade, porém, não implica a necessidade de ele ser autoritário e valer-se de expedientes como a punição, a ameaça e a desqualificação do estudante, os quais apenas enfraquecem as relações de confiança necessárias ao bom desenvolvimento dos processos educativos. Por outro lado, certos níveis de problematização podem ter lugar nas práticas pedagógicas que envolvam crianças, já que há questionamentos que quaisquer indivíduos, mesmo os de baixa faixa etária, podem fazer e compreender.

Nos anos terminais do ensino fundamental e no ensino médio, o emprego de recursos como dramatização, júri simulado e discussão de situações-problema que retratem a dialética entre os princípios gerais e os juízos de valor particulares podem contribuir muito para a abertura de espaços dialógicos nas salas de aula. Esse trabalho pode ser desenvolvido transversalmente, como propõem os PCN, ou de forma interdisciplinar, sendo, inclusive, complementado pelo envolvimento de docentes e discentes em atividades como seminários e pro- jetos elaborados em parceria com as comunidades situadas no entorno da escola. Além disso, problematizar a incompreensão discente, isto é, interrogar-se sobre as razões que levam o aluno a pensar e a agir desta ou daquela maneira contribui para não converter os próprios argumentos em respostas apocríticas, fomentando, assim, a negociação das distâncias presentes em todo o processo de aprendizagem.

A educação não é onipotente, não muda radicalmente as sociedades como supunham, no início do século XX, os defensores do otimismo pedagógico. Ela pode, porém, contribuir para os processos de transformação social na medida em que busque problematizar a indiferença, a animosidade, o hedonismo e a adesão irrefletida a crenças, valores e formas de conduta, o que dificilmente ocorre quando o ensino se desenvolve de forma monológica. Já os processos dialógicos e argumentativos abrem perspectivas para que os papéis de orador e de auditório possam ser permutados. Tal permuta permite, ao professor, aprender enquanto ensina e, ao aluno, ensinar enquanto aprende, transformando a escola em um locus no qual os sujeitos se respeitam não porque há relações hierárquicas entre eles, mas porque suas razões, sentimentos e histórias de vida são capazes de interagir. 


\section{Referências}

ABREU, Vanessa Kern; INÁCIO FILHO, Geraldo. A educação moral e cívica - doutrina, disciplina e prática educativa. Revista HISTEDBR On-line, Campinas, n. 24, p. 125-134, dez. 2006.

ARISTÓTELES. Tópicos. São Paulo: Abril Cultural, 1983. (Coleção Os Pensadores).

Ética a Nicômaco. Brasília, DF: Editora da UnB, 1992.

BADIOU, Alain. Ética: um ensaio sobre a consciência do mal. Rio de Janeiro: Relume-Dumará, 1995.

BAUMAN, Zygmunt. Ética pós-moderna. São Paulo: Paulus, 2006.

BRASIL. Ministério da Educação. Parâmetros Curriculares Nacionais: terceiro e quarto ciclos do Ensino Fundamental: apresentação dos temas transversais. Brasília, DF: MEC/SEF, 1998a.

Ministério da Educação. Diretrizes Curriculares Nacionais do Ensino Fundamental. Brasília, DF: MEC/SEF, 1998b. Disponível em: <portal.mec.gov.br/index.php?ttemid=\&gid=852\&option=com>. Acesso em: 21 mai. 2011.

CUNHA, Luiz Antonio. A laicidade em xeque: religião, moral e civismo na educação brasileira 1931/97. 2007. Disponível em: <http://www.nepp-dh.ufrj.br/ole/textos_equipe2.html>. Acesso em: 30 mai. 2011.

DESCARTES, René. Méditations métaphysiques. Paris: Garnier-Flammarion, 1979.

DEWEY, John. A reconstrução das concepções morais. São Paulo: Companhia Editora Nacional, 1958.

GOERGEN, Pedro. Educação moral: adestramento ou reflexão comunicativa? Educação e Sociedade, v. 22, n. 76, p. 147-174, out. 2001.

Educação para a responsabilidade social: pontos de partida para uma nova ética. In: SEVERINO, Francisca E. Santos (Org.). Ética e formação de professores. São Paulo: Cortez, 2011. p. 93-129.

IMBERT, Francis. A questão da ética no campo educativo. Petrópolis: Vozes, 2001.

KANT, Immanuel. Réflexions sur l'éducation. Paris: Vrin, 1996.

. Crítica da razão prática. Lisboa: Edições 70, 1997.

KOYRÉ, Alexandra. Considerações sobre Descartes. Lisboa: Presença, 1986.

LA TAILLE, Yves de. Vergonha, a ferida moral. Petrópolis: Vozes, 2002.

. Construção da consciência moral. Prima Facie, v. 1, n. 2, p. 7-30, 2008.

LALANDE, André. Vocabulário técnico e crítico da filosofia. São Paulo: Martins Fontes, 1993.

LOCKE, John. Ensaio acerca do entendimento humano. São Paulo: Nova Cultural, 1997. (Coleção Os Pensadores).

MAFFESOLI, Michel. A sombra de Dionísio. Rio de Janeiro: Graal, 1985.

. Au creux des apparences: pour une éthique de l'esthétique. Paris: Plon, 1990.

MEYER, Michel. 0 filósofo e as paixões. Porto: Edições Asa, 1994.

Questões de linguagem, retórica, razão e sedução. Lisboa: Edições 70, 1998.

Qu'est-ce que l'argumentation? Paris: Vrin, 2005. 
OLIVEIRA, Manfredo Araújo de. Ética e práxis histórica. São Paulo: Ática, 1995.

ORGANIZAÇÃO DAS NAÇÕES UNIDAS. Declaração universal dos direitos humanos. 1948. Disponível em: <http://portal.mj.gov. br/sedh/ct/legis_intern/ddh_bib_inter_universal.htm>. Acesso em: 04 set. 2010.

PERELMAN, Chaïm. Justice et raison. Bruxelles: Editions de L'Université, 1972.

La philosophie du pluralisme et la nouvelle rhétorique. Revue Internationale de Philosophie, n. 127-128, p. 5-17, 1979. . Ética e direito. São Paulo: Martins Fontes, 1996.

PERELMAN, Chaïm; OLBRECHTS-TYTECA, Lucie. Tratado da argumentação: a nova retórica. São Paulo: Martins Fontes, 1996.

PLATÃO. Mênon. In: Diálogos, v. 5. São Paulo: Edições Profissionais Ltda, 2010. p. 109-160.

ROUSSEAU, Jean Jacques. Emílio, ou Da educação. São Paulo: Martins Fontes, 1995.

SCHELLING, Friedrich. Oeuvres métaphysiques. Paris: N.R.F, 1980.

TUGENDHAT, Ernst. Lições sobre ética. Petrópolis: Vozes, 1997.

Recebido em: 07.09.2010

Aprovado em: 21.06.2011

Renato José de Oliveira é doutor em Educação pela Pontifícia Universidade Católica do Rio de Janeiro (PUC-RJ, 1996), mestre em Educação pela Fundação Getúlio Vargas do Rio de Janeiro (FGV-RJ, 1990), graduado em Engenharia Química pela Universidade do Estado do Rio de Janeiro (UERJ, 1982) e licenciado em Química pela Universidade do Estado do Rio de Janeiro (UERJ, 1984). Atualmente é professor associado I da Universidade Federal do Rio de Janeiro (UFRJ) e coordenador do Grupo de Pesquisas sobre a Ética na Educação (GPEE). Suas principais áreas de atuação são filosofia da educação e currículo, atuando principalmente nos seguintes temas: relações entre ética, argumentação e educação, análise retórica do discurso e questões epistemológicas da educação. 